\title{
SARS-CoV-2 diagnosis: a single-centre experience
}

\author{
Ion Maruntelu ${ }^{1,2}$, Andreea Mirela Caragea ${ }^{1,2}$, Maria Tizu ${ }^{1,2}$, lleana Constantinescu ${ }^{1,2 *}$
}

\section{Author Affiliations:}

1. Department of Immunology and Immunology of Transplant, Carol Davila University of Medicine and Pharmacy, Bucharest, Romania

2. Centre of Immunogenetics and Virology, Fundeni Clinical Institute, Bucharest, Romania

\author{
* Corresponding Author: \\ lleana Constantinescu, Professor, \\ Centre of Immunogenetics and Virology, \\ Fundeni Clinical Institute, 258 Fundeni Avenue, \\ Bucharest, 022328, Romania. \\ Phone: +40744341984 \\ E-mail: ileana.constantinescu@imunogenetica.ro
}

DOI

10.25122/jml-2021-0064

\section{Dates}

Received: 18 February 2021

Accepted: 27 March 2021

The coronavirus disease 2019 (COVID-19) was declared a pandemic by the World Health Organization (WHO) on the $11^{\text {th }}$ of March 2020. In Romania, there have been 983,217 confirmed cases and 24,386 deaths. We aim to show our experience at the Fundeni Clinical Institute in the diagnosis of Severe Acute Respiratory Syndrome Coronavirus-2 (SARS-CoV-2) infection in both patients and health care personnel. Swab samples were collected for extraction of the SARS-CoV-2 RNA from 29380 patients and health care personnel. We have combined three real-time reverse transcription-polymerase chain reaction (RTPGR) assays for the qualitative detection of SARS-CoV-2. Also, the presence of IgG against SARS-CoV-2 nucleoprotein was analyzed in 1068 patients and clinical staff using the chemiluminescence method. Other 50 people were screened post-vaccination for the presence of SARS-CoV-2 antibodies against the spike (S) protein, using the chemiluminescence method as well. The majority of confirmed cases were in adults, $71.3 \%$ of cases being registered in people aged 30-69 years. Most patients diagnosed with SARS-CoV-2 infection (83\%) were admitted to the gastroenterology, hematology, and surgery wards. Our study showed that one-third of people developed antibodies against the nucleocapsid of SARS-CoV-2. SARS-CoV-2 IgG seroprevalence does not vary by gender or age. Also, we noticed the presence of antibodies against the SARS-CoV-2 spike protein in all 50 people post-vaccination that were tested two weeks after the second dose. Due to the increasing number of infected patients with SARS-CoV-2, the new coronavirus pandemic involves a sustained testing effort for an accurate virological diagnosis in both direct and indirect diagnosis.

KEYWORDS: COVID-19, SARS-CoV-2, RT-PCR, anti nucleocapside, anti-protein $\mathrm{S}$, patients and healthcare workers.

ABBREVIATIONS: Ig - immunoglobulin; RNA - ribonucleic acid; RTPCR - reverse transcription-polymerase chain reaction; WHO - World Health Organization. 


\section{JOURNAL of MEDICINE and LIFE}

\section{INTRODUCTION}

In December 2019, many people with acute respiratory syndrome were identified in Wuhan, a city from Hubei, China [1]. In the following months, a similar acute respiratory disease has also been reported worldwide [2]. The World Health Organization (WHO) named the disease coronavirus disease 2019 (COVID-19) and declared it a pandemic in the next few months [3]. The International Committee on Taxonomy of Viruses renamed 2019-nCoV to Severe Acute Respiratory Syndrome Coronavirus-2 (SARS-CoV-2). This virus was detected in different secretions from infected cases (i.e., throat swabs, conjunctival swabs, sputum) [4]. Thus, the main mode of transmission is from one person to another through different types of secretions. People of all ages could be infected, but the risk for complications increases with age [8] and immunological status. Around the world, 71.3 million people have been infected with SARSCoV-2, and more than 1.6 million people have died from the disease, according to the WHO [5]. At the time of writing, there have been 983,217 confirmed cases of COVID-19 and 24,386 deaths in Romania [5].

Full-genome sequencing and phylogenetic analysis indicated that SARS-CoV-2 is a member of the coronavirus family. Determination of SARS-CoV-2 partial genome sequence allowed the development of real-time reverse transcriptase-polymerase chain reaction (RT-PCR) methods for the detection of SARS-CoV-2 [6, 7]. RT-PCR tests were based on RNA-dependent RNA polymerase (RdRp), ORFlab, E, N, and S genes of the SARS-CoV-2 genome [8-11].

We aimed to share our experience at the Fundeni Clinical Institute in the diagnosis of SARS-CoV-2 infection in both patients and health care personnel and to reveal the specific immunization.

\section{MATERIAL AND METHODS}

This study was carried out at the Fundeni Clinical Institute, Bucharest, Romania. Both nasal and oropharyngeal specimens were collected from patients and health care workers, and electronic medical records provided various epidemiological and clinical data.

\section{Real-time reverse transcription-polymerase chain reaction assay for COVID-19}

Swab samples were collected for the extraction of SARS-CoV-2 RNA from 23338 patients and clinical staff. We have approached direct virological diagnosis using three real-time RT-PCR assays for the qualitative detection of SARS-CoV-2 (Bosphore, Anatolia Geneworks, Turkey; Seegene, South Korea; GeneXpert, Cepheid, United States of America). These three assays were used to validate the methods (interassay validation) and also to cover the emergencies for the transplantation procedure. Bosphore Anatolia Geneworks products targeted the orfl ab genome region, $\mathrm{N}$ gene (added in the last version of the kit) and $\mathrm{E}$ gene. Seegene products targeted the $\mathrm{N}$ gene, RNA-dependent RNA polymerase - RdRp and E gene, while GeneXpert SARS-CoV-2 tests detected the E and N2 genes in less than an hour. The GeneXpert SARS-CoV-2 test was used to screen patients before the transplantation procedure. The RT-PCR tests were settled according to the manuscript instructions. Also, the presence of IgG against SARS-CoV-2 nucleoprotein was analyzed in 1068 patients and clinical staff using the chemiluminescence method (SARS-CoV-2 IgG assay, Abbott, Illinois, United States of America). We have started to investigate the anti-spike antibody onset after vaccination with Pfizer, AstraZeneca, and Moderna vaccines.

\section{Statistical analysis}

Statistical analysis was done using the Statistical Package for the Social Sciences (SPSS) version 13.0 software (SPSS Inc). The categorical variables are summarized numbers and percentages.

\section{RESULTS}

We have included in our study all the patients that were tested for before their admission to the hospital. Also, 2382 individuals that are part of the medical staff of the Fundeni Clinical Institute were analyzed. All participants were tested for the SARS-CoV-2 infection. The median age of the patients was 55.72 years, and $52.21 \%$ of them were men. The median age was 46 years for the clinical staff, and $70.44 \%$ of them were women. Patients from the entire country usually come to be treated in our Institute, but most of the patients were from Bucharest-Ilfov (35.5\%). The highest number of SARS-CoV-2 tests was requested from the gastroenterology, hematology, oncology, neurology, and urology wards, which represented $75.49 \%$ of all tests (Table 1). Regarding the patients, the positive rate of the RT-PCR tests was $7.23 \%$. All the patients positive for the SARS-CoV-2 infection had one or more comorbidities (diabetes, obesity and others) and were aged between 1 and 101 years old. The biggest incidence of positive cases (72.42\%) was seen in individuals aged 39-74 years.

The highest number of positive cases was noticed in patients admitted to the hematology and oncology departments, and we have correlated this to their secondary immunodeficiencies (Table 1). 


\section{JOURNAL of MEDICINE and LIFE}

Table 1. Positive and negative RT-PCR tests in the most important wards of the Fundeni Clinical Institute.

\begin{tabular}{|c|c|c|c|}
\hline Row Labels & Negative RT-PCR & Positive RT-PCR & Sum of grand total RT-PCR \\
\hline Gastroenterology & 2345 & 73 & 2418 \\
\hline General Surgery & 989 & 58 & 1047 \\
\hline Hem cell stem transplantation & 102 & 16 & 118 \\
\hline Hematology & 1896 & 161 & 2057 \\
\hline Intensive Care Unit & 63 & 18 & 81 \\
\hline Internal Medicine & 1267 & 72 & 1339 \\
\hline Kidney transplantation & 86 & 6 & 92 \\
\hline Nephrology & 844 & 46 & 890 \\
\hline Neurology & 1177 & 77 & 1254 \\
\hline Oncology & 1591 & 119 & 1710 \\
\hline Pediatric & 343 & 18 & 361 \\
\hline Urology & 2316 & 74 & 2390 \\
\hline
\end{tabular}

Three hundred eighty-nine healthy individuals who were part of the medical staff were also positive for the SARS-CoV-2 infection. Most of the infected medical workers (212) came from the intensive care unit, general surgery, gastroenterology, and hematology departments. The rate of positive RT-PCR results was higher in the case of female health care workers $(n=293)$ than males $(n=96)$.

Also, 1068 patients and health care personnel were screened for the presence of SARS-CoV-2 IgG anti-nucleocapsid antibodies using the chemiluminescence method (Table 2). The test for SARS-CoV-2 IgG antibodies revealed that 253 patients and 157 health workers of the Institute developed IgG antibodies against the virus. Other 50 people (patients and medical staff) were screened post-vaccination for the presence of SARS-CoV-2 antibodies against the spike (S) protein. All of them developed antibodies against SARS-CoV-2 spike protein.

\section{DISCUSSION}

SARS-GoV-2 targets alveolar epithelial cells and enterocytes, leading to Covid-19 [12, 13]. The disease is predominantly characterized by respiratory symptoms and may progress to bilateral interstitial pneumonia, respiratory failure, or acute respiratory distress syndrome (ARDS) [14]. According to a WHO report from March 2021, there have been 983,217 confirmed cases of COVID-19 and 24,386 deaths in Romania [5].

At the Fundeni Clinical Institute, a significant number of RT-PGR tests for the SARS-CoV-2 infection were performed for both admitted patients and medical personnel. Our experience in the interpretation of RT-PCR results revealed at least four possible profiles. The presence of the $\mathrm{E}$ gene without $\mathrm{Orflab} / \mathrm{RdRp}$ and $\mathrm{N}$ genes indicated a possible infection with coronaviruses and retesting is advised. The presence of the E, Orflab/RdRp and N genes at a cycle threshold $(\mathrm{Ct})$ value of less than 30 indicates an infection with the SARSCoV-2 virus. If the Ct value is higher than 30, RT-PCR should be completed with SARS-CoV-2 IgG screening in order to check if the individual was immunized. Immunized patients with positive RT-PCR tests were not considered to be an epidemiological risk. When

Table 2. Results of the anti-SARS-CoV-2 IgG tests.

\begin{tabular}{|l|c|c|c|}
\hline Anti-SARS-CoV-2 IgG & Negative RT-PCR & Positive RT-PCR & No previous RT-PCR \\
\hline Negative & 255 & 38 & 365 \\
\hline Positive & 117 & 78 & 215 \\
\hline Grand total & $\mathbf{3 7 2}$ & $\mathbf{1 1 6}$ & 410 \\
\hline
\end{tabular}




\section{JOURNAL of MEDICINE and LIFE}

only a specific SARS-CoV-2 gene was identified (at a Ct value less than 30), infection with SARS-CoV-2 was confirmed. Otherwise, the RT-PCR test was repeated.

We have noticed a slight predominance of the female gender $(59 \%$ of the total cases, M/F ratio - 0.84$)$ in our positive results. The majority of confirmed cases were in adults, $71.3 \%$ of cases being registered in people aged 30-69 years. Most patients diagnosed with SARS-CoV-2 (83\%) were admitted to the gastroenterology, hematology, and surgery wards. The majority of the patients were immunocompromised. Our findings are similar to Chen et al., who concluded that the SARS-CoV-2 infection seems to affect older men with different comorbidities (i.e., diabetes mellitus and malignancies) [1]. Guo et al. showed that the rate of SARS-CoV-2 positive cases was higher in intensive care units (ICU) compared to the other wards [15]. Anti-SARS-CoV-2 IgG anti-nucleocapsid antibodies were identified in 38.38\% of cases (from 1068 tests). One hundred fifty-seven of the total confirmed RT-PCR cases were registered among the medical staff, and 253 patients were found to be immunized against COVID-19. Our results revealed that a relevant number of people working in the ICU got immunized against SARS-CoV-2 with no signs and symptoms of the disease. One-third of the tested people developed anti-nucleocapsid antibodies against SARS-CoV-2. SARS-CoV-2 IgG seroprevalence was not changed by gender or age. Differences were revealed in immunocompromised people. Concordant results were published by colleagues from China and Spain [16]. In the United States, researchers found that a large number of the population appeared to be unexposed to COVID-19, even in areas where the new coronavirus has become widespread [16].

These findings suggest that complete immunization could not be possible. Transmission pathways are not fully understood until now. As an RNA virus, SARS-CoV-2 has a high rate of mutations that occur during the multiplication cycle of the virus resulting in new viral strains. Therefore, the emergence of a new SARS-CoV-2 strain is conditioned by its ability to multiply and disseminate to susceptible organisms [17]. In order to limit the spread of the epidemic, emergency epidemiological measures (isolation, quarantine, restriction of movement and human contact) should be kept. From December until March 2021, in Romania, only messenger RNA-based vaccines were used. The messenger RNA enters the human cells, where it transmits the necessary information for the production of its viral proteins, against which, subsequently, antibodies will develop. In our center, we noticed the presence of antibodies against SARS-CoV-2 $\mathrm{S}$ protein in all 50 people post-vaccination that were tested by the chemiluminescence method (SARS-CoV-2 IgG assay, Abbott, Illinois, United States of America) two weeks after the second dose. Our preliminary results showed arbitrary units (AU) values higher than 3000 in all these people. During the studied time, we did not have reinfected patients pre- or post-vaccination.

However, we have noticed that anti-nucleocapsid IgG antibodies decreased over time. Unfortunately, anti-spike IgG antibody levels detected after immunization also decreased over time. We are wondering what happens with these antibodies by the end of the year. As for influenza viruses, we think that immunization against SARS-CoV-2 should be done periodically to have a certain protective level of specific antibodies.

\section{CONCLUSIONS}

Due to the increasing number of patients infected with SARS-CoV-2, the new coronavirus pandemic involves a sustained testing effort for an accurate virological diagnosis in both aspects of direct and indirect diagnosis. Upon admission, all patients must be tested for COVID-19. If suspicious (fever, respiratory symptoms), contact precautions must be carried out until a negative PCR result is obtained. This will prevent the hospital from becoming a source of SARS-CoV-2 infection which could spread among the patients and medical staff. Patients aged 30-69 with secondary immunodeficiency were at significant risk of getting infected with the new coronavirus.

Anti-nucleocapsid antibodies revealed after natural infection or anti-spike antibodies that appear post-vaccination do not mean that patients and health care workers could not get infected with the new coronavirus again. We have to keep in mind that SARS-CoV-2 is an RNA virus with a high mutation rate within the genome. Therefore, it is not yet clear how long and how efficient specific anti-SARS$\mathrm{CoV}-2$ antibodies are. More accurate studies are needed to understand the dynamics of the immune response and how both innate and adaptive immunity fights against COVID-19.

\section{ACKNOWLEDGMENTS}

\section{Data availability}

The data that supports the findings of this study are available from the electronic medical records of our institution and can only be accessed with approval of the system manager.

\section{Conflict of interest}

The authors declare that there is no conflict of interest. 


\section{JOURNAL of MEDICINE and LIFE}

\section{REFERENCES}

Chen N, Zhou M, Dong X, Ou J, Gong F, Han Y, O Y, Wang J, Liu Y, Wei Y, Xia J, Yu T, Zhang X, Zhang I. Epidemiological and clinical characteristics of 99 cases of 2019 novel coronavirus pneumonia in Wuhan, China: descriptive study. Lancet. 2020;395(10223):507-513. doi: 10.1016/S0140-6736(20)30211-7. Epub 2020 Jan 30. PMID: 32007143; PMCID: PMC7135076.

2. Du Z, Wang L, Cauchemez S, Xu X, Wang X, Cowling BJ, Meyers LA. Risk for Transportation of Coronavirus Disease from Wuhan to Other Cities in China. Emerg Infect Dis. 2020 May;26(5):1049-1052. doi: 10.3201/ eid2605.200146. Epub 2020 May 17. PMID: 32053479; PMCID: PMC7181905

3. Cucinotta D, Vanelli M. WHO declares COVID-19 a pandemic. Acta Biomed 91:157-160.2020;

4. Li H, Wang Y, Ji M, Pei F, Zhao O, Zhou Y, Hong Y, Han S, Wang J, Wang Q, Li Q, Wang Y. Transmission Routes Analysis of SARS-CoV-2: A Systematic Review and Case Report. Front Cell Dev Biol. 2020;8:618. doi: 10.3389/fcell.2020.00618. PMID: 32754600 , PMCID: PMC7365854.

5. WHO COVID-19 Dashboard. Geneva: World Healt Organization, 2020. Available online: https://covid19.who. int/region/euro/country/ro (Accessed on 04-08-2021).

6. Wu A, Peng Y, Huang B, Ding X, Wang X, Niu P, Meng J, Zhu Z, Zhang Z, Wang J, Sheng J, Quan L, Xia Z, Tan W, Cheng G, Jiang T Genome Composition and Divergence of The Novel Coronavirus (2019-nCoV) Originating in Chin Cell Host Microbe. 2020;27(3):325-328. doi: 10.1016/j.chom.2020.02.001. Epub 2020 Feb 7. PMID: 32035028; PMCID: PMC7154514.

7. Lu R, Zhao X, Li J, et al. Genomic characterisation and epidemiology of 2019 novel coronavirus: implication for virus origins and receptor binding. Lancet.
2020:395(10224):565-574. doi:10.1016/S0140-6736(20)30251-8

8. Corman VM, Landt O, Kaiser M, Molenkamp R, Meijer A, Chu DK, Bleicker T, Brünink S, Schneider J, Schmidt ML, Mulders DG, Haagmans BL, van der Veer B, van den Brink S, Wijsman L, Goderski G, Romette JL, Ellis J, Zambon M, Peiris M, Goossens H, Reusken C, Koopmans MP, Drosten C. Detection of 2019 novel coronavirus (2019-nCoV) by real-time RT-PCR. Euro Surveill. 2020;25(3):2000045. doi: 10.2807/1560-7917.ES.2020.25.3.2000045. Erratum in: Euro Surveill. 2020 Apr;25(14): Erratum in: Euro Surveill. 2020 Jul;25(30): PMID: 31992387; PMCID: PMC6988269.

9. Konrad R, Eberle U, Dangel A, Treis B, Berger A Bengs K, Fingerle V, Liebl B, Ackermann N, Sing A. Rapid establishment of laboratory diagnostics for the novel coronavirus SARS-CoV-2 in Bavaria, Germany, February 2020. Euro Surveill. 2020;25(9):2000173. doi: 10.2807/1560-7917.ES.2020.25.9.2000173 PMID: 32156330; PMCID: PMC706816310.

10. Chan JF, Yip CC, To KK, Tang TH, Wong SC, Leung KH, Fung AY, Ng AC, Zou Z, Tsoi HW, Cho GK, Tam AR, Cheng VC, Chan KH, Tsang OT, Yuen KY. Improved Molecular Diagnosis of COVID-19 by the Novel, Highly Sensitive and Specific COVID-19-RdRp/ Hel Re Hel Real-Time Reverse Transcription-PCR Assay Validat In Vitro and PMID: 32132196; PMCID: PMC7180250.

11. Reusken Chantal B.E.M., Broberg Eeva K, Haagmans Bart, Meijer Adam, Corman Victor M, Papa Anna, Charrel Remi, Drosten Christian, Koopmans Marion, Leitmeyer Katrin, on behalf of EVD-LabNet and ERLI-Net. Laboratory readiness and response for novel coronavirus (2019-nCoV) in expert laboratories in $30 \mathrm{EU} / \mathrm{EEA}$ countries, January 2020. Euro Surveill. 2020;25(6):pii=2000082. https://doi.org/10.2807/1560-7917.ES.2020.25.6.2000082
12. Wrapp D, Wang N, Corbett KS, et al. Cryo-EM structure of the 2019-nCoV spike in the prefusion conformation. Science. 2020;367(6483):1260-1263. doi:10.1126/science.abb2507

13. Ryu G, Shin HW. SARS-CoV-2 Infection of Airway Epithelial Cells. Immune Netw. 2021;21.e3. Published 202 Mar 2. doi:10.4110/in.2021.21.e3

14. Vasarmidi E, Tsitoura E, Spandidos DA, Tzanakis N Antoniou KM. Pulmonary fibrosis in the aftermath of the COVID-19 era (Review). Exp Ther Med. 2020;20(3):2557-2560. doi:10.3892/etm.2020.8980

15. Guo ZD, Wang ZY, Zhang SF, Li X, Li L, Li C, Cui Y, Fu RB, Dong YZ, Chi XY, Zhang MY, Liu K, Cao C, Liu B, Zhang K, Gao YW, Lu B, Chen W. Aerosol and Surface Distribution of Severe Acute Respiratory Syndrome Coronavirus 2 in Hospital Wards, Wuhan, China, 2020. Emerg Infect Dis. 2020 Jul;26(7):1583-1591. doi: 10.3201/eid2607.200885. Epub 2020 Jun 21. PMID: 32275497; PMCID: PMC7323510.

16. Pollán M, Pérez-Gómez B, Pastor-Barriuso R, Oteo J, Hernán MA, Pérez-Olmeda M, Sanmartín JI Fernández-García A, Cruz I, Fernández de Larrea N, Molina M, Rodríguez-Cabrera F, Martín M, Merino-Amador P, León Paniagua J, Muñoz-Montalvo JF, Blanco F, Yotti R; ENE-COVID Study Group. Prevalence of SARS-CoV-2 in Spain (ENE-COVID): a nationwide, population-based seroepidemiological study. Lancet. 2020;396(10250):535-544. doi: 10.1016/S0140-6736(20)31483-5. Epub 2020 Jul 6. PMID: 32645347; PMCID: PMC7336131.

17. Shah Vibhuti Kumar, Firmal Privanka, Alam Aftab, Ganguly Dipyaman, Chattopadhyay Samit: Overview of Immune Response During SARS-CoV-2 Infection: Lesson From the Past. Frontiers in Immunology. 2020;11.2020. doi:10.3389/fimmu.2020.01949 